\title{
Predicting Students' Spiritual and Religious Competence Based on Supervisory Practices and Institutional Attendance
}

\author{
Andrew P. Secor, PhD \\ MidAmerica Nazarene University, Olathe, Kansas, United States \\ (iD) https://orcid.org/oooo-0001-9523-2709 \\ Corinne W. Bridges, EdD \\ Walden University, Minneapolis, Minnesota, United States
}

Contact:apsecor@mnu.edu

\begin{abstract}
Counseling students report a lack of competence in spiritual and religious integration (SRI). As such, counselor educators and supervisors (CES) and students want to understand how to develop SRI competence. Although past research highlights SRI dialogue in training, there exists no clear understanding about the role of faculty supervisor SRI on perceived student competence. The supervision models used to inform the study included (a) the integrated developmental model, (b) the discrimination model, and (c) the spirituality in supervision model (SACRED). The purpose of this study is to determine if master's-level graduate counseling student perceptions of faculty supervisor SRI practices predicts student perceived spiritual competence when considering attendance in faith-based and non-faith-based institutions accredited by the Council for Accreditation of Counseling and Related Education Programs (CACREP). A review of existing literature supports the use of a quantitative, cross-sectional design. An online survey was distributed to students $(n=$ 59) in master's-level CACREP counseling programs, currently in field experience, to measure perceived SRI in supervision and perceived SRI competence. A multiple linear regression reveals a statistically significant predictive relationship between supervisor SRI and perceived student competence as measured by the Spiritual and Religious Competence Assessment and the Spiritual Issues in Supervision Scale. These results inform CES about the importance of SRI and student ability to work with the spiritual and religious beliefs of clients. On this basis, it is recommended that supervisors focus on SRI in supervision. Future research should focus on additional factors related to SRI competence during counselor training.
\end{abstract}

Keywords: counseling, supervision, spirituality, religion

Date Submitted: February 15, 2021 | Date Published: October 19, 2021

\section{Recommended Citation}

Secor, A. P., \& Bridges, C. W. (2021). Predicting students' spiritual and religious competence based on supervisory practices and institutional attendance. Journal of Social, Behavioral, and Health Sciences, 15(1), 244-257. https://doi.org/10.5590/JSBHS.2021.15.1.17

We have no known conflicts of interest. Correspondence concerning this article should be addressed to Andrew Secor, MidAmerica Nazarene University, 2030 E. College Way, Olathe, KS 66062. Email: apsecor@mnu.edu 


\section{Introduction}

The examination and inclusion of spirituality and religion in counseling research and practice has emerged as an area of interest and focus over the last 40 years (Bohecker et al., 2017; Hull et al., 2016; Powers, 2005). The Association for Spiritual, Ethical, and Religious Values in Counseling (ASERVIC, n.d.) developed spiritual competencies, which the American Counseling Association (ACA) endorsed, that indicate how counselors should incorporate spirituality and religion into counseling practice (Bohecker et al., 2017; Cashwell \& Watts, 2010). Existing research includes a review of the role of spirituality and religion from supervisor perspectives, professional perspectives, and client perspectives (Henricksen et al., 2015; Hull et al., 2013; Kim et al., 2015; Stewart-Sicking et al., 2017).

There is a dearth of information examining the perceptions of student experiences of spiritual and religious integration in supervision and the overall effect of supervisor integration practices on student competence. Students report that they desire discussion about spirituality and religion but that they receive conflicting messages from professors about the role of these two areas in practice (Adams, 2012; Hull et al., 2013). An examination of programs accredited by the Council for Accreditation of Counseling and Related Educational Programs (CACREP, 2017) and those not accredited by CACREP found that non-CACREP program graduates reported higher levels of spiritual integration than those students attending CACREP programs (Gilliam \& Armstrong, 2012). As a result of mixed perceptions about these messages, concerns by both students and professionals about competence when entering professional practice-and a continued interest in the topics of spirituality and religion-make examining how supervisor integration practices influence student perceived competence a timely subject.

The integration of spirituality and supervision in the mental health field is a widely researched and discussed topic (Bohecker et al., 2017; Hull et al., 2016; Shafranske, 2016; Stewart-Sicking et al., 2017; Vieten et al., 2013). The ASERVIC, a division of the ACA, developed 14 spiritual competencies that counselors should possess to provide competent counseling services (ASERVIC, n.d.; Cashwell \& Watts, 2010). The 14 spiritual competencies fall within six categories: (a) culture and worldview, (b) counselor self-awareness, (c) human and spiritual development, (d) communication, (e) assessment, and (f) diagnosis and treatment (Hull et al., 2016). These competency areas each include expectations of counselors when working with clients to develop an understanding of the role of spirituality and religion in their clients' lives.

Historically, members of the mental health profession viewed spirituality and religion as problems influencing the client condition, rather than seeing them as sources of support (Stewart-Sicking et al., 2017; Vieten et al., 2013). Due to this view, many training programs do not integrate spirituality or religion into their courses or the supervisory experience (Vieten et al., 2013).

According to Vieten et al. (2013), counselors should expect the issue of spirituality and religion to come up in sessions with their clients, given the number of individuals who report a desire to address a concern related to these issues. However, counselors in practice report feeling inadequate to address issues related to spirituality and religion when clients present with these concerns (Plumb, 2011; Vieten et al., 2016). Gilliam and Armstrong (2012) found that many faculty members in counseling programs recognize the importance of integrating spirituality and religion during supervision, but they note that accredited counseling programs integrate spirituality and religion infrequently compared to nonaccredited programs. Morrison et al. (2009) found that counselors use spiritual interventions during their sessions more frequently than in the past, but that at least half of all counselors do not use spiritual interventions during sessions. Further, counselors who use spiritual interventions tend to do so as a result of postgraduate training rather than as the result of exposure to these topics during graduate school (Morrison et al., 2009). 
Over the last 15 years, professionals developed instruments to evaluate the integration practices of supervisors and the competence of counselors in practice (Fluellen, 2007; McInnes Miller, 2003). The Spiritual Issues in Supervision Scale (SISS) and the Spiritual and Religious Competence Scale (SARCA) served as the primary instruments for this study. Both of these instruments use a Likert scale to rate competence and integration of spirituality and religion (Fluellen, 2007; McInnes Miller, 2003). The SISS consists of 30 questions that assess supervision integration practices (McInnes Miller, 2003). The SARCA consists of 34 questions that assess the counselors perceived competence in the area of spiritual and religious integration (Fluellen, 2007). These instruments emerged as a result of continued interest in spiritual and religious integration practices. In addition, models and guides supporting the integration of spiritualty and religion into supervision emerged (Hull et al., 2016; Ross et al., 2013; Stewart-Sickey et al., 2017).

Hull et al. (2013) found that supervisees and supervisors saw discussion about spirituality and religion as important during the supervision process. Although this study demonstrated the importance of dialogue between supervisors and supervisees, the study did not examine the influence of spiritual and religious integration during supervision and its potential impact on student competence.

\section{Null and Alternative Hypotheses}

Despite a wealth of information on the topic of spiritual integration, a gap in literature exists in that there is little research about how students perceive the spiritual integration practices of their supervisors, and how those practices affect their competence.

\section{The Null Hypothesis}

Perceived spiritual competency of master's-level graduate counseling students in CACREP-accredited programs, who are working with clients in field experience, is not statistically significantly predicted by student perception of their faculty supervisor's integration of spirituality into clinical supervision. In addition, attendance in a program housed within a faith-based or non-faith-based institution does not statistically significantly predict spiritual competence as measured by the Spiritual Issues in Supervision Scale, the Spiritual and Religious Competence Assessment, and the demographic questionnaire.

\section{The Alternative Hypothesis}

Perceived spiritual competency of master's-level graduate counseling students in CACREP-accredited programs, who are working with clients in field experience, is statistically significantly predicted by students' perception of their faculty supervisors integrating spirituality into clinical supervision. In addition, attendance in a program housed within a faith-based or non-faith-based institution does statistically significantly predict spiritual competence as measured by the Spiritual Issues in Supervision Scale, the Spiritual and Religious Competence Assessment, and the demographic questionnaire.

It is not known whether spiritual integration in supervision predicts competency as reported by counseling students. Therefore, information from this study could inform the integration practices of supervisors during the training process. In addition, the results of the study could assist in developing a stronger therapeutic relationship and enhance how professional associations approach the topic of spiritual integration.

\section{Method}

\section{Research Design and Procedure}

This was a quantitative nonexperimental predictive study that examined three variables: (a) studentperceived spiritual and religious competence, (b) student-perceived spiritual and religious integration by the 
clinical supervisor, and (c) student institutional attendance at either a faith-based or non-faith-based CACREP-accredited counseling program. The predictor variables included spiritual and religious integration, as well as the type of institution a counseling student attended. The criterion variable was the participant's perceived level of spiritual and religious competence.

Quantitative instruments were used to collect data for the variables in the study. The 30-item SISS measured student perceptions about supervisor spiritual and religious integration practices (McInnes Miller, 2003). The 34-item SARCA measured student spiritual and religious competence (Fluellen, 2007). Finally, the demographic questionnaire provided data for the third variable, institutional attendance (faith-based institution vs. non-faith-based institution).

Study participants received an email via listserv, university research platform, or from a faculty member involved in the counseling program with an invitation to participate in the study. Participants completed the survey via SurveyMonkey. All data was reviewed by the principal investigator for completion and accuracy prior to use.

\section{Participants}

Students attending a masters-level CACREP-accredited counseling program in the United States, who were enrolled in practicum or internship, and received clinical supervision, were eligible to participate in the study. A nonprobability convenience sampling method was used to obtain the sample for the study. Based on a review of existing literature, convenience sampling is a common method employed when working with students (Stangor, 2015). Convenience sampling offered an optimal method of obtaining participants because no registry of all students attending CACREP accredited programs existed at the time of the study. A total of 75 students consented to participate, with a total of 59 who completed the study. Students were recruited from known counseling listservs, regional universities, and an opt-in university research database. Doctoral students and counseling students who were enrolled in non-CACREP accredited programs were excluded from the study.

CACREP-eligible programs included areas of study such as (a) addiction, (b) career, (c) clinical mental health, (d) college, (e) community, (f) gerontology, (g) marriage, couple, and family, (h) mental health, (i) school, (j) student affairs, (k) student affairs and colleges, and (l) dually accredited clinical rehabilitation/clinical mental health counseling (CACREP, 2016).

\section{Measures}

Demographics. The principal investigator used a demographic questionnaire to collect data about the predictor variable of the type of institution the participant attended. The basis for development was on best practices for multicultural sensitivity. Respondents were asked for information related to: (a) age, (b) gender, (c) race, (d) sexuality, (e) religious background, (f) state of residence, (g) CACREP program track, (h) whether the institution was public or private, and (i) the type of CACREP institution (faith-based or non-faith-based).

Spiritual Integration. Participants completed the Spiritual Issues in Supervision Scale to rate the level of perceived spiritual integration during supervision. The questionnaire included 30 items about the integration of spirituality and religion during supervision and used a 5-point Likert scale to rate the level of integration. The scale ranged from 1 (spiritual issues are never addressed) to 5 (spiritual issues are frequently discussed; McInnes Miller, 2003). Cronbach's alpha was .94, which indicated good internal consistency. An analysis of the reliability of the subscales produced scores of .79 to .89 (McInnes Miller et al., 2006). Content validity was demonstrated based on a review of the questions by experts during development (McInnes Miller et al., 2006). 
Spiritual Competence. Participants completed the Spiritual and Religious Competence Scale to rate the level of perceived spiritual and religious competence. The questionnaire included 34 items that addressed the participants perceived competence in the integration of spirituality and religion during therapy and used a 6point Likert scale. The scale ranged from 1 (strongly disagree) to 6 (strongly agree; Fluellen, 2007).

Cronbach's alpha was .91, which indicated good internal consistency. An analysis of the reliability of the subscales produced scores of .87 to .94 (Fluellen, 2007). Experts in the field reviewed the questions and determined the SARCA demonstrated both face and content validity (Fluellen, 2007).

\section{Data Analysis}

Data collected were downloaded from SurveyMonkey via an Excel spreadsheet and then were entered into SPSS Statistics 25. Descriptive statistics included spiritual integration, spiritual competence, and type of institution attended. Data used in the study were complete and without missing responses. Data analysis was limited to complete cases following removal of cases during data cleaning. A linear-regression analysis was completed to examine the predictive effect of integration on competence. A correlational analysis was completed to review the relationship between the variables.

\section{Results}

Of the 59 participants who completed the survey, 48 were female, 10 were male, and one identified as transgender (see Table 1). Participant ages ranged from 22-54 years, with an average age of 33.22 years (see Table 1). Participants reported a range of sexual orientations, with heterosexual $(n=50)$ being the most frequently reported sexual orientation. For race/ethnicity, six participants indicated African American/Black, two indicated Asian (East, South, Asian American), 43 indicated Caucasian/White, five indicated Latino or Hispanic American, one indicated Middle Eastern, and two indicated mixed race. Forty-six participants indicated they attended a private institution, and 13 reported attending a public institution. A range of CACREP track areas were reported, with Clinical Mental Health Counseling (CMHC; $n=31$ ) being the most frequently reported CACREP track. Participants also indicated a range of religious identifications, with Christian $(n=24)$ and nondenominational Christian $(n=10)$ being the most frequently reported religious affiliations. Finally, participants spanned 16 states across the United States. The most frequently reported states were Kansas $(n=28)$ and Missouri $(n=15)$. For complete data, see Tables 1, 2, and 3. For descriptive statistics, see Table 4 . 
Table 1. Gender, Sexual Orientation, Race Demographics

\begin{tabular}{llrr}
\hline & Variable & n & Percent \% \\
\hline Gender & Female & 48 & 81.4 \\
& Male & 10 & 16.9 \\
Transgender & 1 & 1.7 \\
Orientation & & & \\
& & & \\
& Bisexual & 5 & 8.5 \\
& Heterosexual & 50 & 84.7 \\
& Lesbian & 2 & 3.4 \\
Race & Other/not listed & 1 & 1.7 \\
& Prefer not to report & 1 & 1.7 \\
& African American/Black & 6 & \\
& Asian (East, South, Asian & 2 & 10.2 \\
& American) & & 3.4 \\
& Caucasian/White & 43 & 72.9 \\
& Latino or Hispanic American & 5 & 8.5 \\
& Middle Eastern & 1 & 1.7 \\
& Mixed race & 2 & 3.4 \\
\hline
\end{tabular}

Table 2. Religion and Spirituality Demographics

Religious affiliation

$\begin{array}{lcc}\text { Faith-based } & 47 & 79.7 \\ \text { Non-faith-based } & 12 & 20.3\end{array}$

Participant religion

\begin{tabular}{lrr} 
Catholic & 6 & 10.2 \\
Christian & 24 & 40.7 \\
Christian, nondenominational & 10 & 16.9 \\
I am spiritual but do not have religion & 7 & 11.9 \\
I believe in something I call “God” but & 1 & 1.7 \\
do not have a religion & & \\
Lutheran & 1 & 1.7 \\
Methodist & 4 & 6.8 \\
Mormon/Latter-Day Saints & 1 & 1.7 \\
Muslim-Other & 1 & 1.7 \\
Other label, religious & 1 & 1.7 \\
Other & 1 & 1.7 \\
Pagan & 1 & 1.7 \\
Pentecostal & 1 & 1.7 \\
\hline
\end{tabular}


Table 3. Education and Residence Demographics

\begin{tabular}{|c|c|c|c|}
\hline & Variable & $n$ & Percent \% \\
\hline \multicolumn{4}{|c|}{ Public/private school } \\
\hline & Private & 46 & 78 \\
\hline \multirow[t]{7}{*}{ CACREP program } & Public & 13 & 22 \\
\hline & $\begin{array}{l}\text { Clinical Mental Health } \\
\text { Counseling }\end{array}$ & 31 & 52.5 \\
\hline & $\begin{array}{l}\text { Clinical Mental Health } \\
\text { Counseling and Clinical } \\
\text { Rehabilitation Counseling }\end{array}$ & 1 & 1.7 \\
\hline & Community Counseling & 2 & 3.4 \\
\hline & $\begin{array}{l}\text { Marital, Couple, and Family } \\
\text { Counseling/Therapy* }\end{array}$ & 3 & 5.1 \\
\hline & $\begin{array}{l}\text { Marriage, Couple, and } \\
\text { Family Counseling }\end{array}$ & 16 & 27.1 \\
\hline & Mental Health Counseling & 6 & 10.2 \\
\hline \multicolumn{4}{|l|}{ State of residence } \\
\hline & Colorado & 1 & 1.7 \\
\hline & Florida & 1 & 1.7 \\
\hline & Idaho & 2 & 3.4 \\
\hline & Illinois & 2 & 3.4 \\
\hline & Indiana & 1 & 1.7 \\
\hline & Iowa & 1 & 1.7 \\
\hline & Kansas & 28 & 47.5 \\
\hline & Massachusetts & 1 & 1.7 \\
\hline & Missouri & 15 & $25 \cdot 4$ \\
\hline & North Dakota & 1 & 1.7 \\
\hline & Oklahoma & 1 & 1.7 \\
\hline & Ohio & 1 & 1.7 \\
\hline & Pennsylvania & 1 & 1.7 \\
\hline & Rhode Island & 1 & 1.7 \\
\hline & Texas & 1 & 1.7 \\
\hline & Virginia & 1 & 1.7 \\
\hline
\end{tabular}

${ }^{*}$ CACREP lists these programs as separate program areas. 
Table 4. Descriptive Statistics and Predictor Variable Correlations

\begin{tabular}{lccccc}
\hline & $M$ & $S D$ & $N$ & SISS & Faith-based \\
\hline SARCA & 161.55 & 19.28 & 59 & .42 & -.096 \\
SISS & 86.53 & 22.73 & 59 & - & -.096 \\
Faith-based & - & - & 59 & - & - \\
\hline
\end{tabular}

Note. Non-faith-based was the reference group/intercept.

\section{Statistical Assumptions}

A linear regression analysis on spiritual and religious competence, based on spiritual issues in supervision and institutional affiliation (faith-based and non-faith-based), was conducted. The alpha level was set at .05. Spiritual and religious competence scores met the required model assumptions for normality, homoscedasticity, and linearity upon comprehensively reviewing: (a) skewness, (b) kurtosis, (c) box plots, (d) scatterplots, (e) histograms, and (f) Shapiro-Wilk. Scatterplots were reviewed for linearity, and it was determined that no curvilinear relationships existed between the predictor variables and the criterion variable. A review of the histograms associated with each variable also demonstrated a normal distribution. Descriptive statistics are reported in Table 4.

\section{Correlational Analysis}

Correlations between all variables were assessed. Between spiritual and religious competence and spiritual issues in supervision, there was a positive, moderate, but not statistically significant relationship, $r=0.42, p<$ .05. Between spiritual and religious competence and institutional affiliation, there was a negative, minute, but not statistically significant relationship, $r=-.10, p>.05$. Between spiritual issues in supervision and institutional affiliation, there was a negative, small, but not statistically significant relationship, $r=-.10, p>$ .05. A report of the descriptive statistics is provided in Table 4.

\section{Multiple Regression Analysis}

There was a statistically significant relationship between (a) spiritual and religious competence, (b) spiritual issues in supervision, and (c) institutional affiliation, $F(2,56)=6.09, p<.05$. A moderate effect was noted with $18.0 \%$ of the variance accounted for in the model, $R 2=.180$, but with a more conservative adjusted rs $2=$ $15.0 \%$ of the variance accounted for in the model. Spiritual issues in supervision were statistically significant predictors of spiritual and religious competence and accounted for $17.6 \%(R 2=.176)$, but more conservatively, $14.7 \%$ ( $r s 2=0.147)$ of the variance accounted for in the model. Institution affiliation was not a statistically significant predictor of spiritual and religious competence and accounted for $0.9 \%(R 2=.009)$, but more conservatively, $-0.8 \%$ ( $r s 2=-.008$ ) of the variance accounted for in the model. A list of results is provided in Table 5 .

Table 5. Multiple Regression Results for Integration and Institutional Attendance

\begin{tabular}{lccccccc}
\hline \multicolumn{1}{c}{ Predictor } & $\mathrm{B}$ & $\mathrm{SE}$ & $\beta$ & $t$ & $p$ & $R^{2}$ & $r s^{2}$ \\
\hline SISS & .351 & .103 & .414 & 3.40 & .001 & .176 & .147 \\
Faith-based & -2.675 & 5.778 & -.056 & -.463 & .645 & .009 & -.008 \\
\hline
\end{tabular}

Note. Non-faith-based was the reference group/intercept. 


\section{Discussion}

To date, this is one of the first studies to examine student perceptions of supervisor spiritual and religious integration during training and if such integration predicts perceived spiritual and religious competence. Henricksen et al. (2015) reported that students believed that discussion of spirituality and religion during supervision was vital to the development of competence. At the time of the current study, the question of whether discussion of spiritual and religious matters in supervision affects competence was unanswered. However, in the present study, students confirmed and extended the findings of Henricksen et al., as there was a statistically significant predictive relationship between perceived integration of spirituality and religion in supervision and perceived competence. The results extend what is known about the role that institutional affiliation plays in the development of spiritual and religious competence. Most students reported a variety of perspectives offered across academic settings about integrating spirituality and religion in counseling (Adams, 2012; Gilliam \& Armstrong, 2012; Henricksen et al., 2015).

Results from the present study, however, did not demonstrate a statistically significant predictive relationship between perceived competence and attendance in a faith-based or non-faith-based institution. Based on this finding, the supervisory relationship has more to do with student-perceived competence than where they receive their training. This finding extends what is known about the role of supervision in the development of spiritual and religious competence during training.

Hull et al. (2013) found that students deem conversation about spirituality and religion during supervision to be important. When viewed as a whole, the results of the study support this notion and expand the research to support a predictive relationship between integration and competence among the sample. Dialogue about how to integrate spirituality and religion into supervision during training should continue.

Gilliam and Armstrong (2012) found differences in the integration practices of supervisors and the experiences of students. While this study did not address the differences between programs accredited by the Council for Accreditation of Counseling and Related Educational Programs (CACREP, 2017) and nonCACREP-accredited programs (when looking at CACREP-accredited programs), the principal investigator found no statistically significant predictive relationship between spiritual and religious competence and attendance in a faith-based or non-faith-based CACREP program. But, although there was no predictive relationship between spiritual and religious competence and attendance of a faith-based or non-faith-based CACREP institution, the regression analysis did indicate a statistically significant relationship between spiritual integration, institutional affiliation, and spiritual and religious competence when examined together. This finding extends existing knowledge about the type of institution, in that the institution alone was not a significant predictor of spiritual and religious competence among students in the present sample.

According to the literature, exploration of spiritual and religious issues during counseling sessions has received mixed responses from students (Adams, 2012; Gilliam \& Armstrong, 2012). Adams (2012) found that nearly $40 \%$ of counselors (students and professionals) did not believe discussion of spiritual and religious matters is appropriate during a counseling session. Counseling students also indicated uncertainty about including spirituality and religion in the treatment planning process (Adams, 2012). Adams also reported that students felt they could remain objective throughout the counseling process when taking spirituality and religion into account.

In the present study, students confirmed that, more often than not, they did not address the topic of spirituality and religion during treatment planning or assessment discussions in supervision. Reflecting on integration during supervision, most students reported only occasionally or less frequently discussing spirituality and religion in other areas of their clients' lives. Students did report increased rates of discussion 
about spirituality and religion in supervision when engaged in self-reflection or when considering values or the topic of religion specifically.

Responses to questions about integration confirmed that students tended to feel ambivalent about addressing spirituality and religion with their clients. Student responses to these questions provided additional insight into responses offered in the Adams (2012) study by suggesting that infrequent or occasional conversation during supervision, to some extent, contributed to mixed responses about addressing the topic of spirituality and religion in general and in specific areas, such as treatment planning and assessment of client concerns. In evaluating a statement about not encouraging clients to express their spiritual and/or religious beliefs or practices in therapy, $83.6 \%$ of the respondents slightly disagreed, disagreed, or strongly disagreed, indicating that, among this sample, most students encouraged their clients to share their religion or spirituality and did not find this discussion problematic. Responses to this question align with previous research indicating that students believe that conversations about spirituality and religion are important (Adams, 2012).

Henricksen et al. (2015) stated that counseling students reported a lack of growth related to spiritual and religious integration during training. These students also indicated that spirituality and religion were necessary topics for discussion during training, and that counselor educators should work to develop opportunities for training during their academic experience (Henricksen et al., 2015). Participants in the present study stated that opportunities for self-exploration occurred at least occasionally (34\%) or more frequently (42.19\%), indicating that they felt there was an opportunity for personal growth. When asked specifically about addressing spirituality and religion within conversations in the supervisory relationship, $51 \%$ of respondents indicated that the topic was never addressed or was less than occasionally addressed. Responses to these questions suggest that students had increased opportunities in supervision to self-reflect and engage in personal growth, thereby demonstrating an experience that differed from that of the students who responded in the Henricksen et al. (2015) study. Although students perceived their supervisors as less likely to address spirituality and religion in the context of the supervisory relationship, they indicated that they had personal and professional growth experiences.

The conceptual framework for this study encompassed three supervisory models for the counseling profession: the Integrated Developmental Model (IDM), Spirituality in Supervision Model (SACRED), and Bernard's Discrimination Model (DM). Together, these models address the development and process of supervision, as well as a mechanism for intentionally fostering competence among counseling professionals and students. Within the IDM of supervision, supervisees at the Level 1 stage receive limited training and are highly dependent on their supervisor (Bernard \& Goodyear, 2014). Supervisees at Level 2 feel confident enough to make some decisions themselves but still require structure and support offered by a competent supervisor (Bernard \& Goodyear, 2014). While there was a statistically significant relationship between perceived spiritual and religious integration and perceived spiritual competence, as reported by students, the respondents in this sample were at a stage of clinical development in which they required a high degree of education from their supervisors or were at a place of differentiating from their supervisors, generally Level 1.

Respondents indicated a perception of competence largely based on interaction and direction from their supervisor. Students indicated a lack of perceived integration during supervision in areas such as assessment, treatment planning, and conceptualization, which are clinical areas of significance in the IDM model (Bernard \& Goodyear, 2014). To foster competence in students, supervisors need to identify specific methods of introducing the topic of spirituality and religion to assess for and improve overall competence. It is important to note that the clinical supervisor is responsible for helping to guide students in their mastery of specific skills (Bernard \& Goodyear, 2014). Given the role of the supervisor in creating opportunities for growth, it is understandable that a particular institutional religious affiliation would not necessarily predict increased competence, and that there was not a statistically significant predictive relationship between spiritual and religious competence and attendance at a faith-based or non-faith-based counseling program. 
In light of the historical disparity in views about spiritual and religious integration (Vieten et al., 2013), it is likely that most supervisors do not possess the training or skill required to integrate these two factors into supervision. Ross et al. (2013) developed the SACRED model as a way to help supervisors integrate spirituality and religion into supervision to foster competence. After a review of responses to individual questions throughout the survey, students reported that they had discussions only occasionally about spirituality and religion, with an average score of 84 for the SISS out of a total possible score of 170, which indicates frequent discussion about spiritual and religious matters during supervision (McInnes Miller, 2003). In contrast, respondents reported a mean score of 134 on the SARCA out of a possible total score of 180 (Fluellen, 2007). The closer the score is to 180 , the more competent the person feels related to spiritual and religious integration (Fluellen, 2007). All three models of supervision include interventions or roles that indicate that supervisors are responsible for creating safety in the relationship that allows for such conversations, or that they are responsible for challenging students to consider various counseling-related skills to foster competence (Bernard \& Goodyear, 2014).

After review of the mean scores across both surveys, results indicated that students not only felt greater competence when they experienced integration during supervision, but they also reported perceived competence at a greater degree than actual integration. Approximately $26 \%$ of respondents indicated they discussed spirituality and religion related to assessment more than occasionally. With the conceptualization process considered, approximately $25 \%$ of respondents indicated they discussed spirituality and religion more than occasionally. Approximately $43 \%$ of respondents reported they discussed spirituality and religion more than occasionally when asked about self-reflection. In the area of spiritual and religious development, the most frequent response from participants was that supervisors occasionally (34\%) provided opportunities for personal self-reflection, while approximately $43 \%$ of respondents indicated more frequently participating in personal self-reflection. After reviewing responses on the SARCA about personal development, the principal investigator found that $86 \%$ of respondents reported they engaged in developmentally appropriate reviews of their beliefs related to spirituality and religion. According to the data, students reported that they engaged in conversation related to the themes in the SACRED model at least occasionally.

In Bernard's Discrimination Model (DM) of supervision, supervisors use the roles of educator, consultant, and counselor to assist supervisees in the development of counseling skills (Bernard \& Goodyear, 2014). Within the DM supervision experience, supervisors consider (a) process/intervention ability, (b) conceptual ability, and (c) personalization of the therapist (Bernard \& Goodyear, 2014). As mentioned earlier, students perceived that their supervisors integrated discussion about personalization on a more regular basis. It is reasonable to suspect that most supervisors see their role as creating opportunities for personal growth via selfexamination, which would have contributed to why over $75 \%$ of students reported opportunities to consider how their beliefs factored into their understanding of working with clients spiritual or religious beliefs.

Interestingly, even though assisting students in their conceptual ability is a focus of the DM, the majority of students reported they perceived that their supervisors never discussed or only occasionally discussed the process of conceptualization from a religious or spiritual perspective. When looking at the process or intervention aspect of supervision, only approximately $10 \%$ of students reported that supervisors discussed treatment planning frequently or more than occasionally. Approximately $20 \%$ indicated they had discussions about spirituality or religion when working with a trauma client frequently or more than occasionally. Students reported with most frequency that they perceived their supervisors addressed spirituality and religion within the three primary foci of the DM of supervision only occasionally. Because supervisors use various roles (such as, consultant or counselor) to assist students in their development, it is possible that students might not have recognized their supervisors' attempts to help them in these areas based on their stage of clinical development (Bernard \& Goodyear, 2014). 
When viewed together, the models of supervision practice provided a foundation for the development of competence among student counselors. The use of various roles and techniques allowed supervisors to consider the developmental stage of their supervisees along with specific process needs (Bernard \& Goodyear, 2014). The SACRED model enhanced knowledge of integration in supervision by providing specific factors for supervisors to consider as they strive to integrate spirituality and supervision in a developmentally appropriate and process-oriented manner (Ross et al., 2013).

\section{Limitations}

Limitations of the study included: (a) difficulty in obtaining a complete sampling frame (complete listing of all eligible participants), (b) the use of a nonprobability sample (convenience sampling), and (c) a potential low response rate, due to the use of an online survey and participant interest in the study topic. Limitations to generalizability included a large number of respondents from the states of Kansas and Missouri. Additionally, nearly $80 \%$ of respondents indicated attendance at a faith-based institution, and $78 \%$ reported their institution was private although public institutions comprise the majority of CACREP-accredited counseling programs.

\section{Recommendations for Future Research}

While results from this study offer insight into the development of competence in spiritual and religious matters during faculty clinical supervision, additional research is needed to determine what factors contribute to competence. Researchers could expand the study to include different geographical locations in the United States. A larger sample size that includes more students from public institutions could provide additional information about student perceptions and would offer better representation in the sample. Further, a qualitative study could illuminate in-depth understanding of the factors that contribute or predict spiritual and religious competence. Researchers could focus on the role of culture in the integration of spirituality and religion.

\section{Conclusion}

Spiritual and religious integration during the training process is vital to the development of competent students. The literature is clear that students and professionals find discussion and integration of spirituality and religion important and necessary (Adams, 2012; Henricksen et al., 2015; Hull et al., 2013).

While the relationship between the variables was minute to moderate and not statistically significant, data indicated that students perceived that supervisor integration practices, in the area of spirituality and religion, predicted their perceived level of competence in practice when examining the multiple linear regression analysis. Students did not, however, indicate that the type of institution alone predicted their overall competence.

Students did report that the supervisory relationship served a greater role in the development of spiritual and religious competence, and it warrants continued examination of methods to increase supervisor competence and comfort when integrating spirituality and religion during faculty supervision. Providing these opportunities throughout training-regardless of whether the institution is faith-based or not-could increase the chances of graduating students who can navigate these issues with their clients. Upon review of specific questions from the SISS and the SARCA, students reported supervisors integrated spirituality and religion when discussing supervisees personal background and when offering opportunities for self-reflection more so than when addressing clinical issues (such as, treatment planning and diagnosis), demonstrating a perceived lack of attention 
Use of this data offers an opportunity for supervisors to reevaluate the methods used to assist students in the development of spiritual and religious integration. Supervisors have a chance to consider ways to enhance discussion when treatment planning and conceptualizing a client's problem. In addition, supervisors (as leaders in the counseling profession) can advocate for educational standards in the area of religious and spiritual integration and an examination of other factors that contribute to growth in this area. Researchers could examine the influence of curricular adjustment on spiritual and religious competence among students. Qualitative researchers could expand the understanding of ways students perceive the experience of spiritual and religious integration during faculty supervision and what they see as most helpful to their development in this area. Researchers could then offer, with additional detail, the best ways for supervisors to teach and encourage growth during clinical training. Finally, researchers could examine the application of spiritual and religious competence during treatment and how clients perceive their therapy experience compared to those who have limited or no spiritual or religious integration.

According to the literature, if students do not receive training that incorporates discussion related to spirituality and religion, it falls to the newly graduated professional to identify mechanisms for generating competence (Plumb, 2011). We must confront the reality of integration, at this moment, as the current state of spiritual and religious integration remains conflicted. Emerging research continues to support the incorporation of spirituality and religion in both supervision and client services, yet many clinicians and supervisors limit or omit this discussion during training.

With the growth in interest in the area of spirituality and religion since the 1970s, it is assumed the profession would be further along in its acceptance of personal beliefs related to spirituality and religion. At a national conference, dialogue between students and seasoned professionals demonstrated that spirituality and religion remained a topic of discomfort and conflict, as it is seen differently than other areas of a person's life, which are asked about freely. The ethical obligations indicated by the ACA, along with accreditation standards enforced by CACREP, warrant that the profession continues to grapple with how to best train students and supervisors in methods of competent spiritual and religious integration.

Leaving training to the recently graduated student, in this area, creates a gap that may go unfilled. This lack of training puts client care at risk of reduced efficacy. Existing research and the results from this study demonstrate that, while many improvements occurred over the years, there is still a great deal of work to do to consistently bring this important part of clinical work into the supervision setting. 


\section{References}

Adams, J. R. (2012). Spiritual issues in counseling: What do students perceive they are being taught? Counseling and Values, 57(1), 66-80. https://doi.org/10.1002/j.2161-007x.2012.00009.x

Association for Spiritual, Ethical, and Religious Values in Counseling. (n.d.). Competencies for addressing spiritual and religious values in counseling. https://aservic.org/spiritual-and-religious-competencies/

Bernard, J. M., \& Goodyear, R. K. (2014). Fundamentals of clinical supervision (5th ed.). Pearson.

Bohecker, L., Schellenberg, R., \& Silvey, J. (2017). Spirituality and religion: The ninth CACREP core curriculum area. Counseling and Values, 62(2), 128-143. https://doi.org/10.1002/cvj.12055

Cashwell, C. S., \& Watts, R. E. (2010). The new ASERVIC competencies for addressing spiritual and religious issues in counseling. Counseling and Values, 55(1), 2-5. https://doi.org/10.1002/j.2161007x.2010.tboo018.x

Council for Accreditation of Counseling and Related Educational Programs. (2017). CACREP annual reports. CACREP. http://cacrep.org/wp-content/uploads/2019/05/CACREP-2016-Annual-Report.pdf

Fluellen, S. J. (2007). Development of the spiritual and religious competency assessment (SARCA): An instrument to measure competency in supervisees (9597) [Doctoral dissertation, Oklahoma State University]. OSU Dissertations. https://hdl.handle.net/11244/7398

Gilliam, T. H., \& Armstrong, S. A. (2012). Spirituality and counseling supervision: Current practices of boardapproved supervisors. The Clinical Supervisor, 31(1), 25-41.

https://doi.org/10.1080/07325223.2012.671718

Henricksen, R. C., Jr., Polonyi, M. A., Bornsheuer-Boswell, J. N., Greger, R. G., \& Watts, R. E. (2015). Counseling students' perceptions of religious/spiritual counseling training: A qualitative study. Journal of Counseling and Development, 93(1), 59-69. https://doi.org/10.1002/j.15566676.2015.00181.x

Hull, C. E., Suarez, E. C., \& Hartman, D. (2016). Developing spiritual competencies in counseling: A guide for supervisors. Counseling and Values, 61(1), 111-126. https://doi.org/10.1002/cvj.12029

Hull, C. E., Suarez, E. C., Sells, J. N., \& Miller, M. M. (2013). Addressing spiritual dialogue in supervision: Comparing supervisor and supervisee perceptions. Journal of Psychology and Christianity, 32(1), 30-42. http://search.proquest.com/docview/1357043273?accountid $=14872$

Kim, N.-Y., Huh, H.-J., \& Chae, J.-H. (2015). Effects of religiosity and spirituality on the treatment response in patients with depressive disorders. Comprehensive Psychiatry, 6o, 26-34.

https://doi.org/10.1016/j.comppsych.2015.04.009

McInnes Miller, M. M. (2003). Spirituality, gender, and supervisory style in supervision [Doctoral dissertation, Texas Tech University]. https://ttu-ir.tdl.org/ttuir/bitstream/handle/2346/8932/31295019149870.pdf?sequence=1

McInnes Miller, M. M., Korinek, A. W., \& Ivey, D. C. (2006). Integrating spirituality into training: The spiritual issues in supervision scale. The American Journal of Family Therapy, 34(4), 355-372. https://doi.org/10.1080/01926180600553811

Morrison, J. Q., Clutter, S. M., Pritchett, E. M., \& Demmitt, A. (2009). Perceptions of clients and counseling professionals regarding spirituality in counseling. Counseling and Values, 53(3), 183-194. https://doi.org/10.1002/j.2161-007x.2009.tbo0124.x

Plumb, A. M. (2011). Spirituality and counselling: Are counselors prepared to integrate religion and spirituality into therapeutic work with clients? Canadian Journal of Counselling and Psychotherapy, 45(1), 1-16. https://cjc-rcc.ucalgary.ca/article/view/59300 
Powers, R. (2005). Counseling and spirituality: A historical review. Counseling and Values, 49(3), 217-225. https://doi.org/10.1002/j.2161-007x.2005.tb01024.x

Ross, D. K., Suprina, J. S., \& Brack, G. (2013). The spirituality in supervision model (SACRED): An emerging model from a meta-synthesis of the literature. The Practitioner Scholar, 2(1), 68-83.

Shafranske, E. P. (2016). Finding a place for spirituality in psychology training: Use of competency-based clinical supervision. Spirituality in Clinical Practice, 3(1), 18-21. https://doi.org/10.1037/scpooooo98

Stewart-Sicking, J. A., Deal, P. J., \& Fox, J. (2017). The Ways Paradigm: A transtheoretical model for integrating spirituality into counseling. Journal of Counseling and Development, 95(2), 234-241. https://doi.org/10.1002/jcad.12135

Vieten, C., Scammell, S., Pierce, A., Pilato, R., Ammondson, I., Pargament, K. I., \& Lukoff D. (2016). Competencies for psychologists in the domains of religion and spirituality. Spirituality in Clinical Practice, 3(2), 92-114. https://doi.org/10.1037/scpoooo078

Vieten, C., Scammell, S., Pilato, R., Ammondson, I., Pargament, K. I., \& Lukoff, D. (2013). Spiritual and religious competencies for psychologists. Psychology of Religion and Spirituality, 5(3), 129-144. https://doi.org/10.1037/a0032699

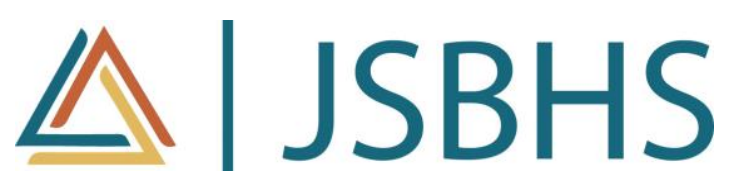

The Journal of Social, Behavioral, and Health Sciences (JSBHS), cosponsored by the College of Health Professionals and the College of Social and Behavioral Sciences at Walden University, is a peer-reviewed, online, interdisciplinary journal focusing on theoretically based research that addresses contemporary national and international issues. JSBHS articles include peer-reviewed research reports, brief reports, comprehensive literature reviews, book reviews, and student research. 